\title{
Influence of Single and Multiple Dry Bands on Critical Flashover Voltage of Silicone Rubber Outdoor Insulators: Simulation and Experimental Study
}

\author{
Arshad ${ }^{1,2, *}$, Muhammad Ali Mughal ${ }^{1}$, Azam Nekahi ${ }^{2}$, Mansoor Khan ${ }^{3}$ and Farhana Umer ${ }^{4}$ \\ 1 Department of Electrical Engineering, Faculty of Engineering and Technology, HITEC University, \\ Taxila 47080, Pakistan; ali.mughal@hitecuni.edu.pk \\ 2 School of Engineering and Built Environment, Glasgow Caledonian University, G4 0BA Scotland, UK; \\ azam.nekahi@gcu.ac.uk \\ 3 School of Electrical Engineering, Sichuan University, Chengdu 610065, China; khan007_bet@yahoo.com \\ 4 Electrical Engineering Department, Islamia University of Bahawalpur, Bahawalpur 63100, Pakistan; \\ farhana.umer@iub.edu.pk \\ * Correspondence: arshad.ali@hitecuni.edu.pk; Tel.: +92-345-255-6729
}

Received: 19 April 2018; Accepted: 17 May 2018; Published: 24 May 2018

\begin{abstract}
Dry band formation on the surface of outdoor insulators is one of the main reasons leading to flashover and power outages. In this paper, a dynamic arc model is proposed for single and multiple dry bands configuration to predict the critical flashover voltage for silicone rubber outdoor insulators. An arc is modelled as a time dependent impedance consisting of a Resistor Inductor Capacitor (RLC) circuit. The effect of dry band location and existence of multiple dry bands on critical flashover voltage is investigated. To validate the proposed model, experiments were conducted in a climate chamber under controlled environmental conditions on rectangular silicone rubber sheets polluted using improved solid layer method based on IEC 60,507. Tests were conducted at different dry band configurations and pollution severity levels. A good correlation was found between experimental results and simulation results. This model can provide a good foundation for the development of mathematical models for station post insulators having multiple dry and clean bands and can be used in the design and selection of outdoor insulators for polluted conditions.
\end{abstract}

Keywords: silicone rubber; dry band; pollution severity; mathematical modelling; flashover voltage

\section{Introduction}

The performance of outdoor high voltage insulators is of high importance for the secure and reliable operation of power system. Outdoor insulators are exposed to various types of stresses during operational environments (electrical, mechanical, environmental, thermal, chemical, etc.). Air pollution is considered one of the considerable problems leading to insulator flashovers. Pollution accumulation on the surface of an outdoor insulator is dependent on the insulator material, inclination, surface wetness along with other chemical and physical properties of the insulator [1]. The contamination affecting the characteristics of outdoor insulators is either in the form of gases e.g., $\mathrm{H}_{2} \mathrm{~S}, \mathrm{NH}_{3}$, conductive solids, such as $\mathrm{NaCl}, \mathrm{MgCl}_{2}, \mathrm{CaSO}_{4}$, or inert materials, such as dust particles. The first two types of contamination effect the surface conductivity of insulator while the third type of pollutant affect the mechanical properties of insulator [2,3]. During rain, cold fog and moist, surface of insulator becomes wet and the solvable pollutants dissolve in water resulting in the flow of leakage current, dry band formation and under certain operating conditions may lead to flashover and power outages. Flashover process of porcelain and glass insulators have been pervasively investigated in 
literature [4,5]. Mathematical models exists in literature for the prediction of flashover voltage and other parameters for porcelain and glass insulators [6-9].

During the last few decades, polymeric insulators are substituting porcelain and glass insulators in power systems due to their superior hydrophobic properties. It has been reported in literature that the flashover process of hydrophobic insulators is different than hydrophilic insulators [10-12]. The arc propagation and pre-flashover conditions for porcelain and glass insulators are well understood but the same does not apply to polymeric insulators [13]. Due to the dynamic surface properties of polymeric insulators, various implications exist in developing of standardized tests and procedures to appraise the performance of polymeric insulators under contaminated conditions [14]. The flashover process of silicone rubber insulators was first investigated experimentally in [10-12]. Due to hydrophobicity transfer characteristics of silicone rubber, low molecular weight (LMW) molecules diffuse through the surface and pollution layer. A thin oil like layer forms on the top of the pollution layer which resist the formation of uniform water layer and leads to the formation of water droplets on the insulator surface. The electric field intensity at the triple junction (water droplet, air and dielectric surface) is high due to the high permittivity of water as compared to surrounding air and silicone rubber [15,16]. Neighboring droplets merge with each other due to the elongation under applied electric stress. Partial arcs appear between neighboring filaments leading to loss of surface hydrophobicity and longer wet regions along the surface. These partial arcs may elongate further leading to flashover under certain conditions. A block diagram representation of the flashover process of silicone rubber outdoor insulators is shown in Figure 1.

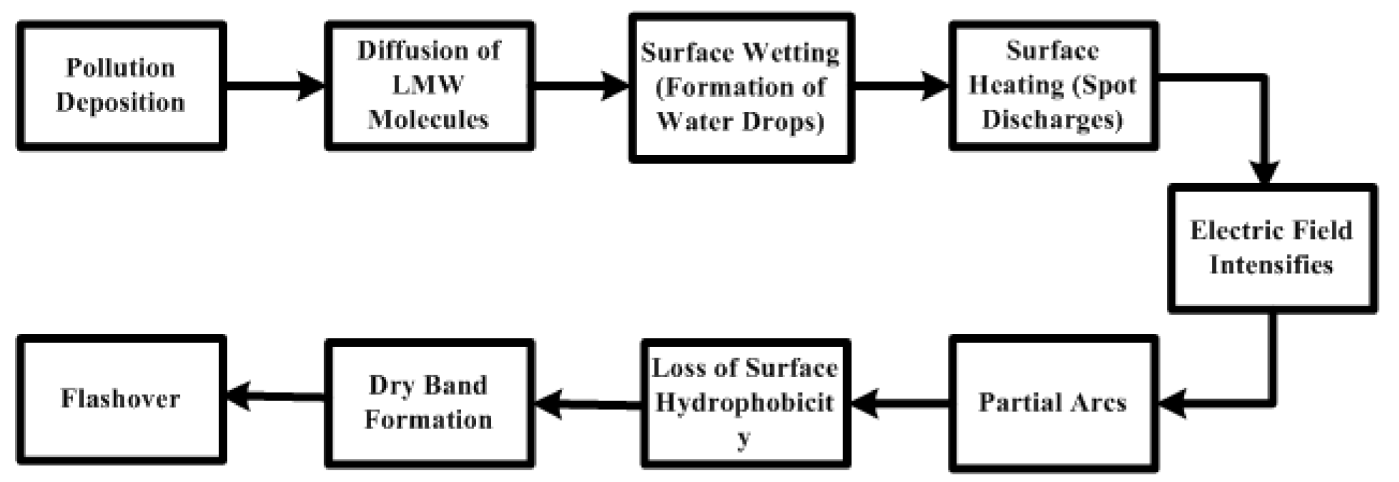

Figure 1. Flashover process of silicone rubber outdoor insulators.

The amount of pollution deposited on the insulator surface and its distribution is dependent on various parameters e.g., surface roughness, insulator orientation, distance from the pollution source, wind speed and direction etc. The distribution of pollution on the insulator surface may not be uniform resulting in non-uniform current density and electric field distribution.

The non-uniformity of leakage current density leads to the formation of dry regions along the insulator surface called 'dry bands'. Dry band formation and resulting discharges is closely related to flashover of insulators. Dry band formation was first studied by Hampton [17] by establishing a relation between applied voltage and dry band resistance. The critical temperature and electric field required for the formation of dry band was investigated by Salthouse [18] and concluded that the dry band width and growth is closely related with the amount of power dissipated in the dry region. A relation between dry band width and temperature was investigated in [19]. Dry band formation along the insulator surface effect the flashover process significantly. A partial arc model is proposed in [20] to predict the flashover voltage of polluted insulators under dry band conditions and concluded that due to partial arcs along the insulator surface, probability of flashover increases. The influence of dry band formation, location and width on the arc inception and flashover voltages were investigated in our previous work [21-23]. These results indicate that dry band formation increase the inception and flashover voltage of polymeric insulators however, the influence of dry band arcing on surface 
hydrophobicity and ageing cannot be predicted from these tests. Mathematical models have been developed for ice-covered insulators in the past to model the effect of air gap width, location and number on the withstand characteristics [24-26]. According to authors knowledge no previous mathematical model incorporates the influence of dry band location and multiple dry bands on the flashover characteristics of polluted polymeric insulators. This paper proposes a new mathematical model for prediction of flashover voltage of silicone rubber insulators under contaminated and dry band conditions. The mathematical model was verified by performing extensive experiments in the laboratory.

\section{Mathematical Model}

Flashover of polluted outdoor insulators is a multifaceted process and various models have been proposed to explain the process of pollution flashover and predict flashover voltage $[17,18,27,28]$. These models are generally divided into two types: static models [27,29] and dynamic models [30-34] Static models are based on the Obenaus model which considers an arc in series with a residual resistance. Dynamic models consider arc as a time dependent impedance consisting of an RLC circuit. Most of the existing mathematical models for polluted outdoor insulators consider a single arc (dry band) on the insulator surface near the energized electrode due to the increase intensity of electric field near that region. From our experimental results, it was observed that dry band formation is dependent on various other parameters and may form anywhere on the insulator surface. Mathematical models for multiple arcs (air gaps) have been developed in the past for ice-covered insulators [35-37]. A new dynamic model for multiple arcs along the surface of polluted insulators have been recently proposed in [38] under impulse voltage conditions. However, this multi-arc model does not consider the dry band location and power frequency voltage. Furthermore, the arc is modelled as RC circuit in [38] instead of RLC and the electromagnetic energy stored and radiated by the arc channel is neglected. In this paper, a modified multi-arc model is proposed by considering the inductive effect of arc and the dry band location.

\subsection{Single Dry Band near High Voltage Electrode}

Mathematical models for plate insulator samples, having a single dry band in series with polluted bands, have been proposed by many researchers in the past. It is presumed that dry band forms near the electrode ends due to the high electric field intensity at these regions. However, experimental results show that dry band may form at other regions along the insulator surface due to the non-uniform pollution deposition. In the case of polymeric insulators, formation of water droplets and their subsequent elongation may result in multiple partial arcs along the insulator surface. In this section, a single dry band near the high voltage electrode is considered. A schematic diagram of a single dry band in series with pollution layer along a rectangular insulator sample is shown in Figure 2.

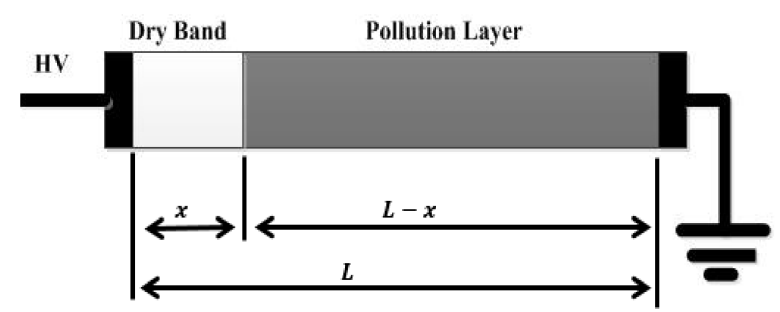

Figure 2. Single dry band near high voltage electrode.

The electrical equivalent circuit for a dry band near high voltage electrode is similar to that proposed by Dhahbi [6] and is shown in Figure 3. The voltage current characteristics of a uniformly polluted sample show that the phase angle difference between voltage and current is negligible. 
This leads to the conclusion that pollution layer is resistive in nature and the polluted band impedance can be replaced by resistance.

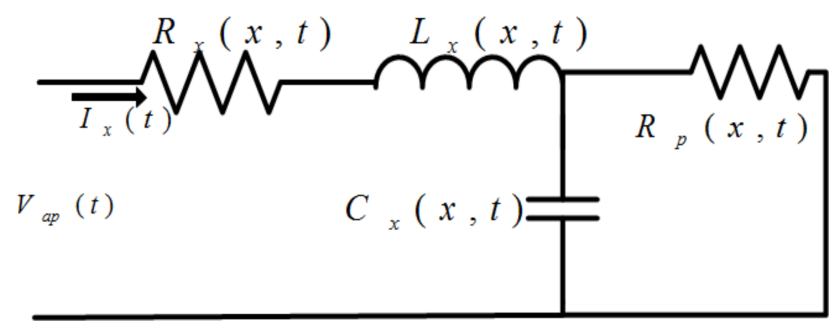

Figure 3. Electric equivalent circuit of insulator sample with single dry band near high voltage electrode.

where:

$$
\begin{gathered}
V_{a p}=\text { Applied power frequency AC voltage } \\
\qquad \begin{array}{c}
R_{x}=\text { Arc resistance } \\
L_{x}=\text { Arc inductance } \\
C_{x}=\text { Arc capacitance }
\end{array}
\end{gathered}
$$

$R_{p}=$ Pollution layer resistance

$$
\begin{gathered}
V_{a p}(t)=I_{x}(t) R_{x}(x, t)+L_{x} \frac{d I_{x}(t)}{d t}+V_{c}(t) \\
I_{x}(t)=C_{x} \frac{d V_{c}(t)}{d t}-\frac{V_{c}(t)}{R_{p}(x, t)}
\end{gathered}
$$

The above equations can be rearranged to obtain the state space representation as given below:

$$
\begin{gathered}
{\left[\begin{array}{c}
\frac{d I_{x}}{d t} \\
\frac{d V_{c}}{d t}
\end{array}\right]=\left[\begin{array}{cc}
-\frac{R_{x}}{L_{x}} & -\frac{1}{L_{x}} \\
\frac{1}{C_{x}} & \frac{1}{R_{p} C_{x}}
\end{array}\right]\left[\begin{array}{l}
I_{x} \\
V_{c}
\end{array}\right]+\left[\begin{array}{c}
\frac{V_{a p}}{L_{x}} \\
0
\end{array}\right]} \\
\dot{x}=A x+B u
\end{gathered}
$$

These state space equations are used to calculate arc current and subsequently flashover voltage.

\subsection{Single Dry Band near Ground Electrode}

The likelihood of dry band development is high near the electrode ends due to the increased electric field intensity at these locations. The flashover voltage for a dry band located near the ground end was found to be higher than high voltage end dry band [21]. To model the effect of a dry band located near the ground electrode, the configuration shown in Figure 4 was considered.

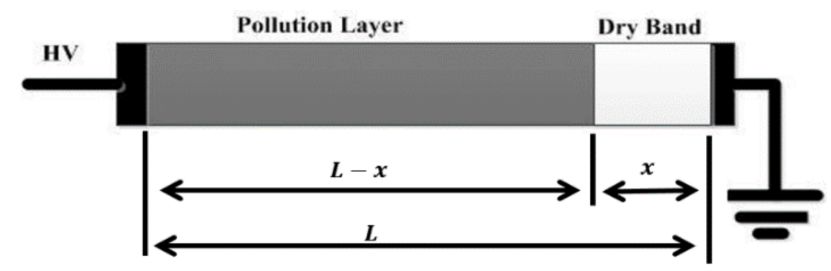

Figure 4. Dry band near ground end.

The electrical equivalent circuit of a ground end dry band configuration is shown in Figure 5. 


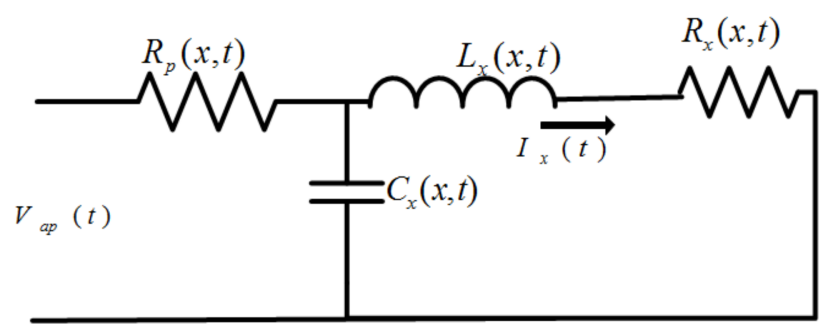

Figure 5. Electrical equivalent circuit for ground end dry band.

$$
\begin{gathered}
V_{a p}(t)=R_{p}(x, t) C_{x} \frac{d V_{c}(t)}{d t}-I_{x}(t) R_{p}(x, t)+V_{c}(t) \\
V_{c}(t)=I_{x}(t) R_{x}(x, t)+L_{x} \frac{d I_{x}(t)}{d t}
\end{gathered}
$$

The state space representation for this model is given below:

$$
\left[\begin{array}{c}
\frac{d I_{x}}{d t} \\
\frac{d V_{c}}{d t}
\end{array}\right]=\left[\begin{array}{cc}
-\frac{R_{x}}{L_{x}} & \frac{1}{L_{x}} \\
\frac{1}{C_{x}} & -\frac{1}{R_{p} C_{x}}
\end{array}\right]\left[\begin{array}{c}
I_{x} \\
V_{c}
\end{array}\right]+\left[\begin{array}{c}
0 \\
V_{a p} \\
\frac{V_{p} C_{x}}{C^{\prime}}
\end{array}\right]
$$

To determine the arc characteristics, it is important to find the relations of different circuit elements. The resistance of the arc channel is a function of arc length and is a time dependent quantity. The arc channel resistance can be calculated from Mayer's equation [39].

$$
\frac{d R_{x}}{d t}=\frac{R_{x}}{\tau}\left(1-\frac{R_{x} I_{x}^{2}}{A}\right)
$$

where:

$$
\begin{gathered}
I_{x}=\text { Arc current } \\
\tau=\text { Arc time constant } \\
A=\text { Static arc constant }
\end{gathered}
$$

The value of time constant $\tau$ and static arc constant are $100 \mu$ s [34] and 340 [40], respectively. The inductance of arc channel is calculated from the simplification used for long air gaps [41]. It has been reported in [42] that if the end effects are not considered, the inductance per unit length of an arc channel is the sum of two inductances: inductance due to the stored electromagnetic energy in the arc channel and inductance due to the electromagnetic field radiation of the current flowing through the channel. The combine inductance of an arc channel is given by:

$$
L_{x}=\frac{\mu_{0}}{2 \pi}\left(0.25+\ln \left(\frac{D_{f}}{r_{x}}\right)\right)
$$

where $D_{f}$ is the distance far from the discharge at which the electromagnetic field is zero and $r_{x}$ is the radius of arc channel [43].

$$
r_{x}=\sqrt{\frac{I_{x}}{1.45 \pi}}
$$

Capacitance of the arc channel is calculated using the spherical approximation as proposed in [44].

$$
C_{x}=2 \pi \varepsilon_{o} \alpha_{x}\left[1+\left(\frac{r_{x}}{L-x}\right)\right]
$$


where:

$$
\alpha_{x}=\left(1-\frac{1}{\sqrt{1+\left[\left(\frac{w}{2 L}\right)\left(\frac{1}{1-\frac{x}{L}}\right)\right]^{2}}}\right)
$$

$w$ is the insulator width. The resistance of the polluted band is calculated using Wilkins model for a plat sample [43].

$$
R_{p}=\frac{1}{2 \pi \sigma}\left[\frac{\pi(L-x)}{w}+\log \left(\frac{w}{2 \pi r_{x}}\right)\right]
$$

where:

$$
\sigma=\text { surface conductivity of pollution layer }
$$

The arc propagation criteria proposed in [45] is employed to calculate the minimum flashover voltage.

$$
\frac{d P_{x}}{d x}>0
$$

where:

$$
P_{x}: \text { Arc power supplied by the source }
$$

\subsection{Single Dry Band in the Middle Region}

Figure 6 shows the sample configuration of a single dry band at the middle region of insulator surface. This model can be represented as combination of two single arcs as shown in Figure 7. The electrical equivalent circuit for the two arc model is shown in Figure 8. For this configuration it is assumed that the arc initiate at the middle region and propagate in both directions.

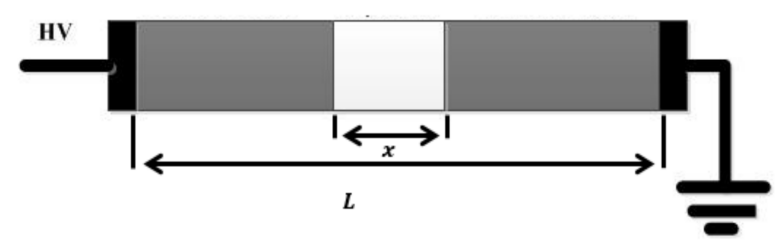

Figure 6. Dry band in the middle region.

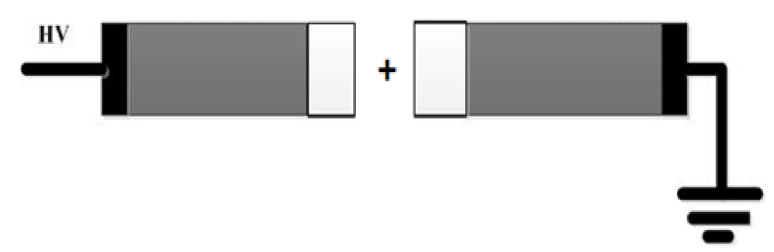

Figure 7. Representation as two arc model.

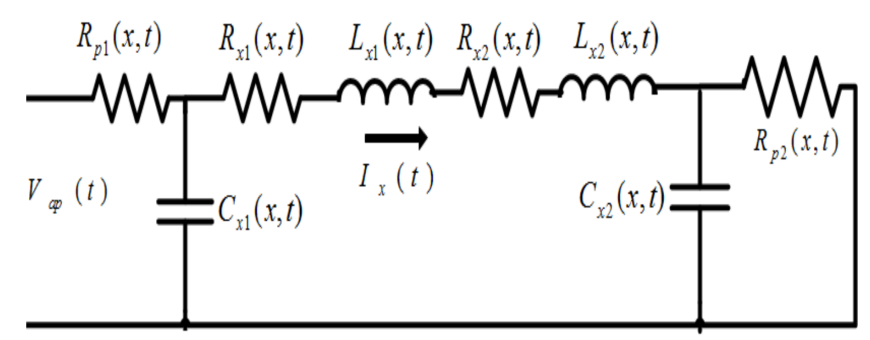

Figure 8. Electrical equivalent circuit of middle dry band. 


$$
\begin{gathered}
V_{a p}(t)=R_{p 1}(x, t) C_{x 1} \frac{d V_{c 1}(t)}{d t}-I_{x 1}(t) R_{p 1}(x, t)+V_{c 1}(t) \\
V_{c 1}(t)=I_{x}(t) R_{x 1}(x, t)+L_{x 1} \frac{d I_{x}(t)}{d t}+I_{x}(t) R_{x 2}(x, t)+L_{x 2} \frac{d I_{x}(t)}{d t}+V_{c 2}(t) \\
I_{x}(t)=C_{x 2} \frac{d V_{c 2}(t)}{d t}-\frac{V_{c 2}(t)}{R_{p 2}(x, t)} \\
{\left[\begin{array}{c}
\frac{d I_{x}}{d t} \\
\frac{d V_{c 1}}{d t} \\
\frac{d V_{c 2}}{d t}
\end{array}\right]=\left[\begin{array}{ccc}
-\frac{R_{x}}{L_{x}} & \frac{1}{L_{x}} & -\frac{1}{L_{x}} \\
\frac{1}{C_{x 1}} & -\frac{1}{R_{p 1} C_{x 1}} & 0 \\
\frac{1}{C_{x 2}} & 0 & \frac{1}{R_{p 2} C_{x 2}}
\end{array}\right]\left[\begin{array}{c}
I_{x} \\
V_{c 1} \\
V_{c 2}
\end{array}\right]+\left[\begin{array}{c}
0 \\
\frac{V_{a p}}{R_{p 1} C_{x 1}} \\
0
\end{array}\right]}
\end{gathered}
$$

where:

$$
\begin{aligned}
& L_{x}=L_{x 1}+L_{x 2} \\
& R_{x}=R_{x 1}+R_{x 2} \\
& \frac{d R_{x 1}}{d t}=\frac{R_{x 1}}{\tau}\left(1-\frac{R_{x 1} I_{x 1}^{2}}{A}\right) . \\
& \frac{d R_{x 2}}{d t}=\frac{R_{x 2}}{\tau}\left(1-\frac{R_{x 2} I_{x 2}^{2}}{A}\right) \\
& L_{x 1}=\frac{\mu_{o}}{2 \pi}\left(0.25+\ln \left(\frac{D_{f}}{r_{x 1}}\right)\right) \\
& L_{x 2}=\frac{\mu_{o}}{2 \pi}\left(0.25+\ln \left(\frac{D_{f}}{r_{x 2}}\right)\right) \\
& r_{x 1}=\sqrt{\frac{I_{x 1}}{1.45 \pi}} \\
& r_{x 2}=\sqrt{\frac{I_{x 2}}{1.45 \pi}} \\
& C_{x 1}=2 \pi \varepsilon_{0} \alpha_{x 1}\left[1+\left(\frac{r_{x 1}}{L-x 1}\right)\right] \\
& C_{x 2}=2 \pi \varepsilon_{0} \alpha_{x 2}\left[1+\left(\frac{r_{x 2}}{L-x 2}\right)\right] \\
& \alpha_{x 1}=\left(1-\frac{1}{\sqrt{1+\left[\left(\frac{w}{2 L}\right)\left(\frac{1}{1-\frac{x 1}{L}}\right)\right]^{2}}}\right) \\
& \alpha_{x 2}=\left(1-\frac{1}{\sqrt{1+\left[\left(\frac{w}{2 L}\right)\left(\frac{1}{1-\frac{x^{2}}{L}}\right)\right]^{2}}}\right) \\
& R_{p 1}=\frac{1}{2 \pi \sigma}\left[\frac{\pi(L-x 1)}{w}+\log \left(\frac{w}{2 \pi r_{x 1}}\right)\right] \\
& R_{p 2}=\frac{1}{2 \pi \sigma}\left[\frac{\pi(L-x 2)}{w}+\log \left(\frac{w}{2 \pi r_{x 2}}\right)\right]
\end{aligned}
$$




\subsection{Two Dry Bands}

Figure 9 shows the sample configuration of an insulator having two dry bands. This configuration can be divided into two single arc model similar to Figure 2 and shown in Figure 10. The electrical equivalent circuit for the two arc model is shown in Figure 11.

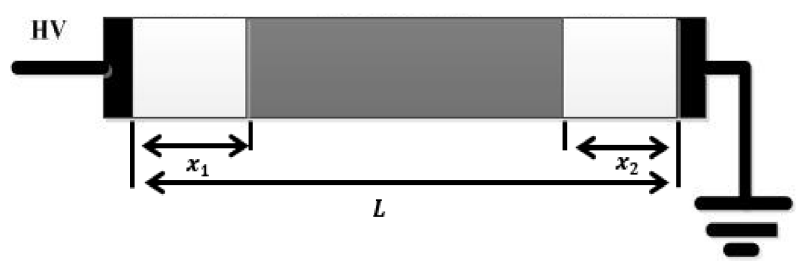

Figure 9. Sample configurations for two dry band neat each electrode.

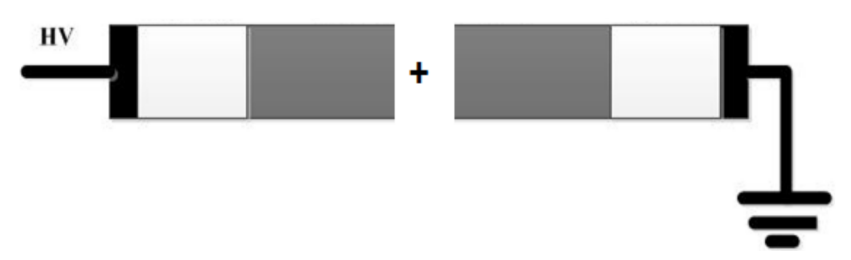

Figure 10. Two single arc model.

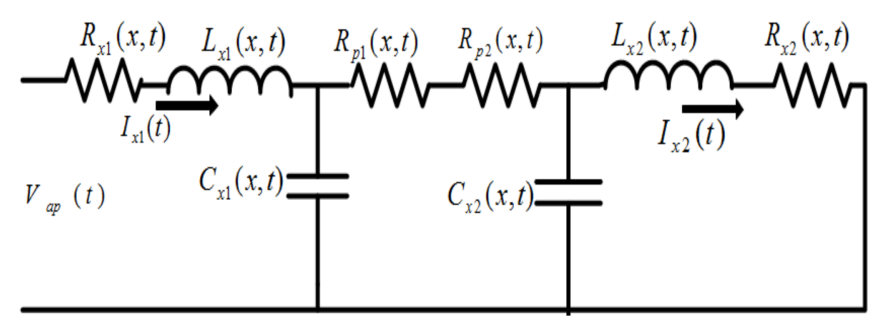

Figure 11. Electrical equivalent circuit of two arc model.

$$
\begin{gathered}
V_{a p}(t)=I_{x 1}(t) R_{x 1}(x, t)+L_{x 1} \frac{d I_{x 1}(t)}{d t}+V_{c 1}(t) \\
I_{x 1}(t)=C_{x 1} \frac{d V_{c 1}(t)}{d t}-\frac{V_{c 1}}{R_{p 1}+R_{p 2}}+\frac{V_{c 2}}{R_{p 1}+R_{p 2}} \\
V_{c 2}(t)=I_{x 2}(t) R_{x 2}(x, t)+L_{x 2} \frac{d I_{x 2}(t)}{d t} \\
I_{x 2}(t)=C_{x 2} \frac{d V_{c 2}(t)}{d t}-\frac{V_{c 1}}{R_{p 1}+R_{p 2}}+\frac{V_{c 2}}{R_{p 1}+R_{p 2}} . \\
{\left[\begin{array}{c}
\frac{d I_{x 1}}{d t} \\
\frac{d I_{x 2}}{d t} \\
\frac{d V_{c 1}}{d t} \\
\frac{d V_{c 2}}{d t}
\end{array}\right]=\left[\begin{array}{cccc}
-\frac{R_{x 1}}{L_{x 1}} & 0 & -\frac{1}{L_{x 1}} & 0 \\
0 & -\frac{R_{x 2}}{L_{x 2}} & 0 & \frac{1}{L_{x 2}} \\
\frac{1}{C_{x 1}} & 0 & \frac{1}{R_{p} C_{x 1}} & -\frac{1}{R_{p} C_{x 1}} \\
0 & \frac{1}{C_{x 2}} & \frac{1}{R_{p} C_{x 2}} & -\frac{1}{R_{p} C_{x 2}}
\end{array}\right]\left[\begin{array}{c}
I_{x 1} \\
I_{x 2} \\
V_{c 1} \\
V_{c 2}
\end{array}\right]+\left[\begin{array}{c}
\frac{V_{a p}}{L_{x 1}} \\
0 \\
0 \\
0
\end{array}\right]}
\end{gathered}
$$

\subsection{Three Dry Bands}

Figure 12 shows the sample configuration of a three dry band model having a dry band near both electrodes and at the middle region. The electrical equivalent circuit is shown in Figure 13. 


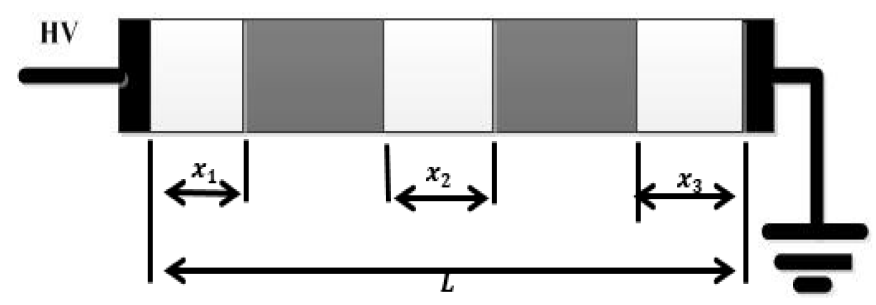

Figure 12. Three dry bands.

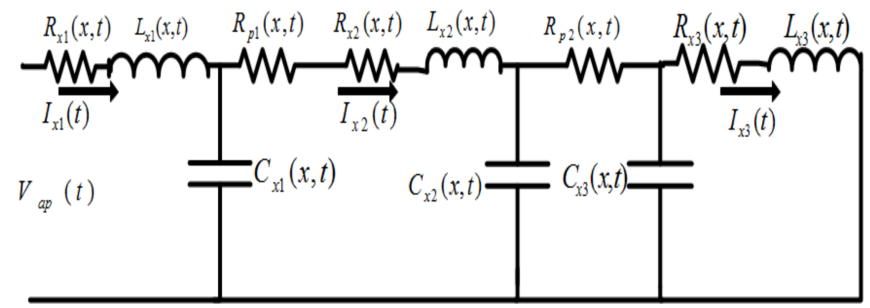

Figure 13. Electrical equivalent circuit of three dry bands model.

$$
\begin{gathered}
V_{a p}(t)=I_{x 1}(t) R_{x 1}(x, t)+L_{x 1} \frac{d I_{x 1}(t)}{d t}+V_{c 1}(t) \\
I_{x 1}(t)=C_{x 1} \frac{d V_{c 1}(t)}{d t}-I_{x 2} \\
V_{c 1}(t)=I_{x 2}(t) R_{p 1}(x, t)+I_{x 2}(t) R_{x 2}(x, t)+L_{x 2} \frac{d I_{x 2}(t)}{d t}+V_{c 2}(t) \\
I_{x 2}=C_{x 2} \frac{d V_{c 2}(t)}{d t}-\frac{V_{c 2}(t)}{R_{p 2}(x, t)}+\frac{V_{c 3}(t)}{R_{p 2}(x, t)} \\
V_{c 2}(t)=R_{p 2}(x, t) C_{x 3} \frac{d V_{c 3}(t)}{d t}-R_{p 2}(x, t) I_{x 3}+V_{c 3}(t) \\
V_{c 3}(t)=R_{x 3}(x, t) I_{x 3}+L_{x 3} \frac{d I_{x 3}(t)}{d t}
\end{gathered}
$$

$$
\left[\begin{array}{c}
\frac{d I_{x 1}}{d t} \\
\frac{d x_{22}}{d t} \\
\frac{d I_{x 3}}{d t} \\
\frac{d V_{c 1}}{d t} \\
\frac{d V_{22}}{d t} \\
\frac{d V_{c 2}}{d t}
\end{array}\right]=\left[\begin{array}{cccccc}
-\frac{R_{x 1}}{L_{x 1}} & 0 & 0 & -\frac{1}{L_{x 1}} & 0 & 0 \\
0 & -\frac{R_{p 1}}{L_{x 2}}-\frac{R_{x 2}}{L_{x 2}} & 0 & \frac{1}{L_{x 2}} & -\frac{1}{L_{x 2}} & 0 \\
0 & 0 & -\frac{R_{x 3}}{L_{x 3}} & 0 & 0 & \frac{1}{L_{x 3}} \\
\frac{1}{C_{x 1}} & \frac{1}{C_{x 1}} & 0 & 0 & 0 & 0 \\
0 & \frac{1}{C_{x 2}} & 0 & 0 & \frac{1}{R_{p 2} C_{x 2}} & -\frac{1}{R_{p 2} C_{x 2}} \\
0 & 0 & \frac{1}{C_{x 3}} & 0 & \frac{1}{R_{p 2} C_{x 3}} & -\frac{1}{R_{p 2} C_{x 3}}
\end{array}\right]\left[\begin{array}{c}
I_{x 1} \\
I_{x 2} \\
I_{x 3} \\
V_{c 1} \\
V_{c 2} \\
V_{c 3}
\end{array}\right]+\left[\begin{array}{c}
\frac{V_{a p}}{L_{x 1}} \\
0 \\
0 \\
0 \\
0 \\
0
\end{array}\right]
$$

where:

$$
\begin{gathered}
\frac{d R_{x 3}}{d t}=\frac{R_{x 3}}{\tau}\left(1-\frac{R_{x 3} I_{x 3}^{2}}{A}\right) \\
L_{x 3}=\frac{\mu_{0}}{2 \pi}\left(0.25+\ln \left(\frac{D_{f}}{r_{x 3}}\right)\right) \\
r_{x 3}=\sqrt{\frac{I_{x 3}}{1.45 \pi}} \\
C_{x 3}=2 \pi \varepsilon_{0} \alpha_{x 3}\left[1+\left(\frac{r_{x 3}}{L-x 3}\right)\right]
\end{gathered}
$$




$$
\begin{aligned}
\alpha_{x 3} & =\left(1-\frac{1}{\sqrt{1+\left[\left(\frac{w}{2 L}\right)\left(\frac{1}{1-\frac{x 3}{L}}\right)\right]^{2}}}\right) \\
R_{p 3} & =\frac{1}{2 \pi \sigma}\left[\frac{\pi(L-x 3)}{w}+\log \left(\frac{w}{2 \pi r_{x 3}}\right)\right]
\end{aligned}
$$

Based on the above mathematical expressions, a simple algorithm was used to compute the critical flashover voltage under various dry band conditions. The proposed algorithm was implemented in Matlab to calculate flashover voltage. The algorithm is represented as a flow chart as shown in Figure 14. Sample dimensions, pollution layer conductivity and configurations, applied voltage, and certain initial conditions were used as input parameters. If the arc propagation criteria described above is not fulfilled, the voltage is increased further until the arc propagates and flashover occurs.

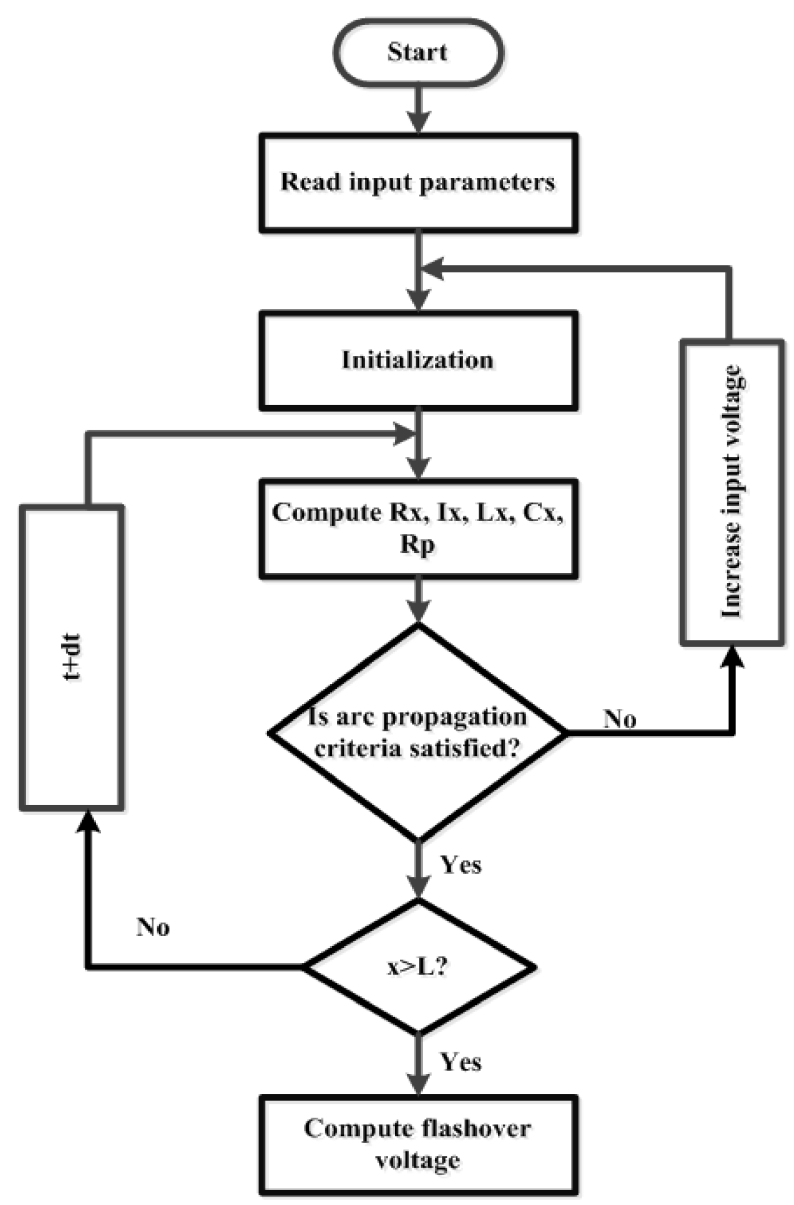

Figure 14. Flow chart of flashover voltage computation.

\section{Model Validation}

\subsection{Experimental Setup}

Figure 15 shows the experimental setup used to prove the validity of the proposed model. HTV silicone rubber sheets of $10 \mathrm{~cm}$ length, $4 \mathrm{~cm}$ wide, and $0.6 \mathrm{~cm}$ thick were used for experiments. Samples were energized inside a climate chamber under different climate conditions (ambient temperature, relative humidity and fog rate). The samples were energized using a $50 \mathrm{~Hz}, 0-100 \mathrm{kV}$ power transformer. Various samples were prepared with different ESDD and NSDD levels and 
dry band configurations. $1 \mathrm{~cm}$ wide clean and dry bands were inserted near the ground electrode, energized electrode and in the middle region.

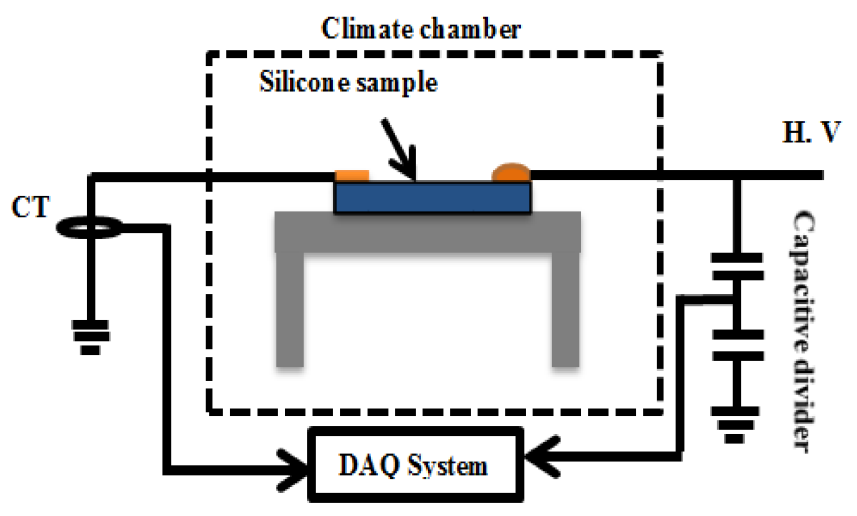

Figure 15. HV test setup.

Figure 16 shows the sample configurations used for experiments. Further details about artificial pollution and high voltage test method can be found in our previous work [22].

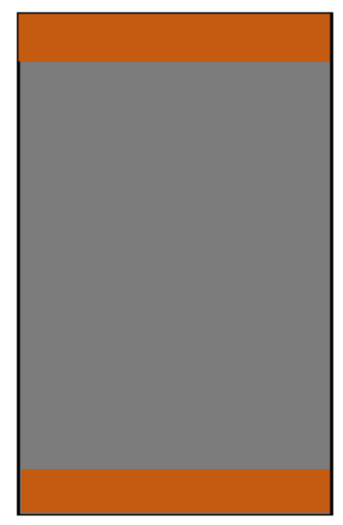

(a)

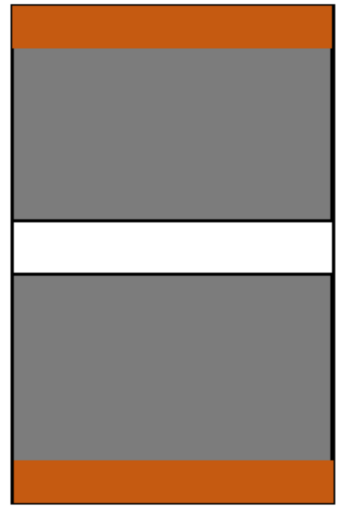

(c)

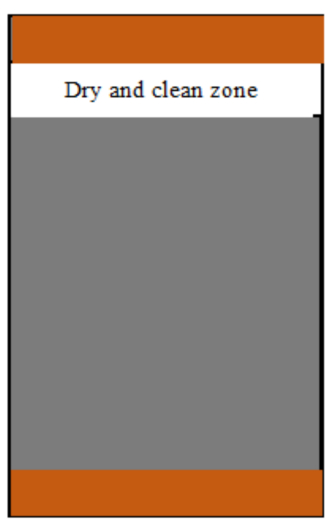

(b)

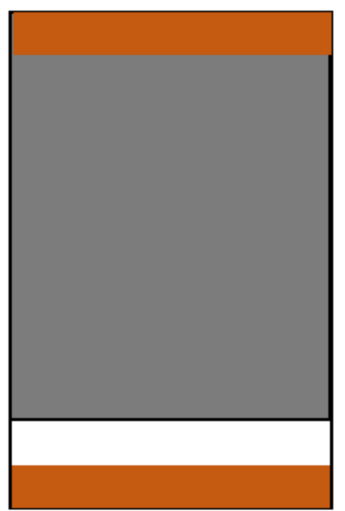

(d)

Figure 16. Cont. 


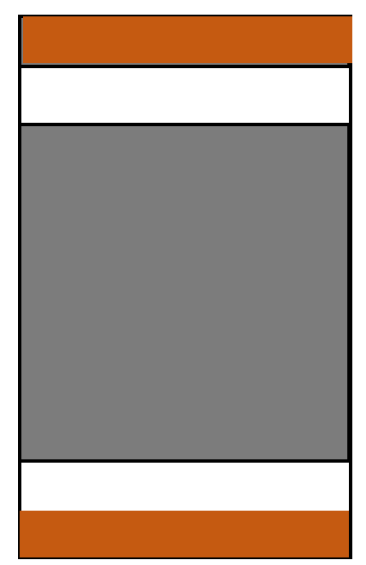

(e)

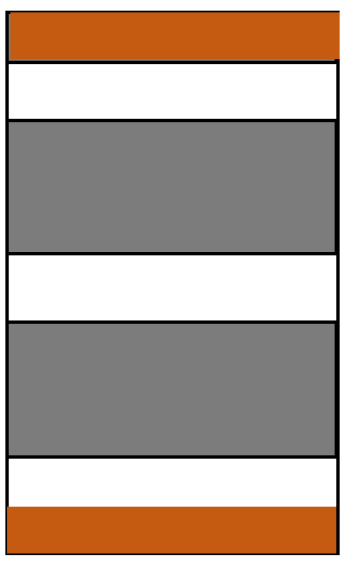

(f)

Figure 16. Sample configurations: (a) uniform pollution layer; (b) dry band near HV electrode (c) dry band near the middle region (d) dry band near ground electrode (e) Dry bands near high voltage and ground electrode (f) Dry bands near middle region, high voltage and ground electrode.

\subsection{Results and Discussions}

To validate the mathematical model, a comparison of simulated and experimental result was carried out at different pollution severity levels and dry band locations. The flashover voltage of a uniformly polluted silicone rubber sheet at various ESDD values is shown in Figure 17. The flashover voltage decreased as the pollution severity level increased. Figure 17 also shows that the experimental and simulation results are in good agreement. For ESDD values greater than $0.30 \mathrm{mg} / \mathrm{cm}^{2}$ change in flashover voltage is less noticeable as compared to low values of ESDD which may be due to the saturation of surface resistance of pollution layer.

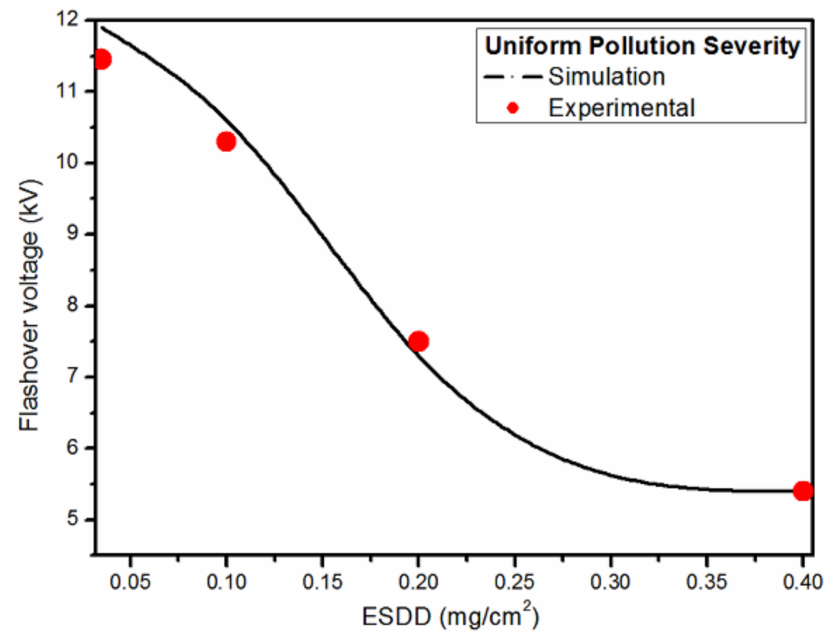

Figure 17. Flashover voltage at different NSDD values for a uniform pollution layer.

Figure 18 shows the experimental and simulation results for a sample configuration where a single dry band of $1 \mathrm{~cm}$ width is located near the energize electrode. A decrease in flashover voltage was noticed with increase in ESDD. The difference between simulation and experimental results is high at lower values of ESDD and become negligible at higher values. However, overall a good agreement was found between experimental and simulation results. 


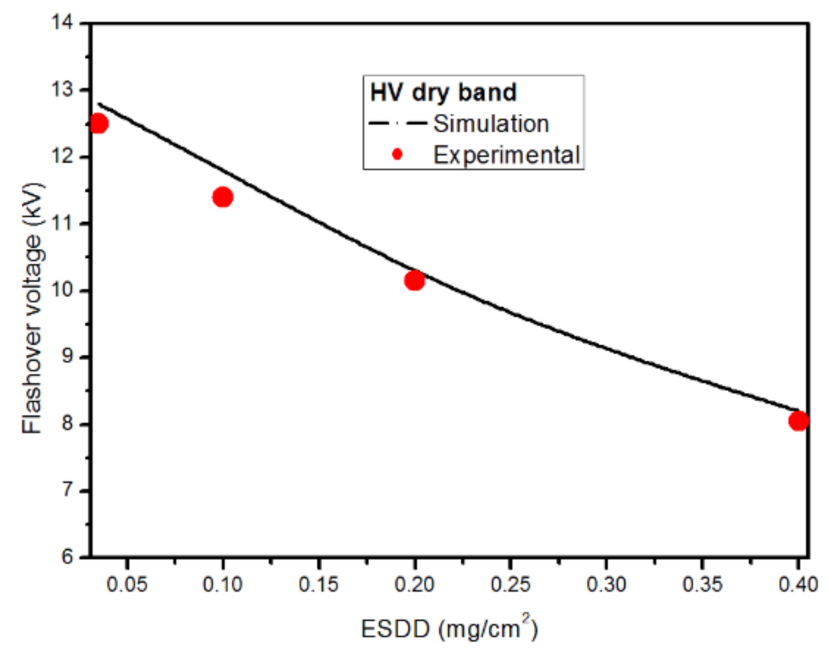

Figure 18. Flashover voltage for a high voltage end dry band at different ESDD levels.

Figure 19 shows simulation and experimental results of critical flashover voltage when a $1 \mathrm{~cm}$ dry band is located at the ground electrode. The flashover voltage found in this case is higher than the high voltage end dry band configuration. This difference in flashover voltage can be attributed to the low arc propagation velocity and arc current in the case of ground end dry band. Overall, the simulation and experimental results were in good agreement.

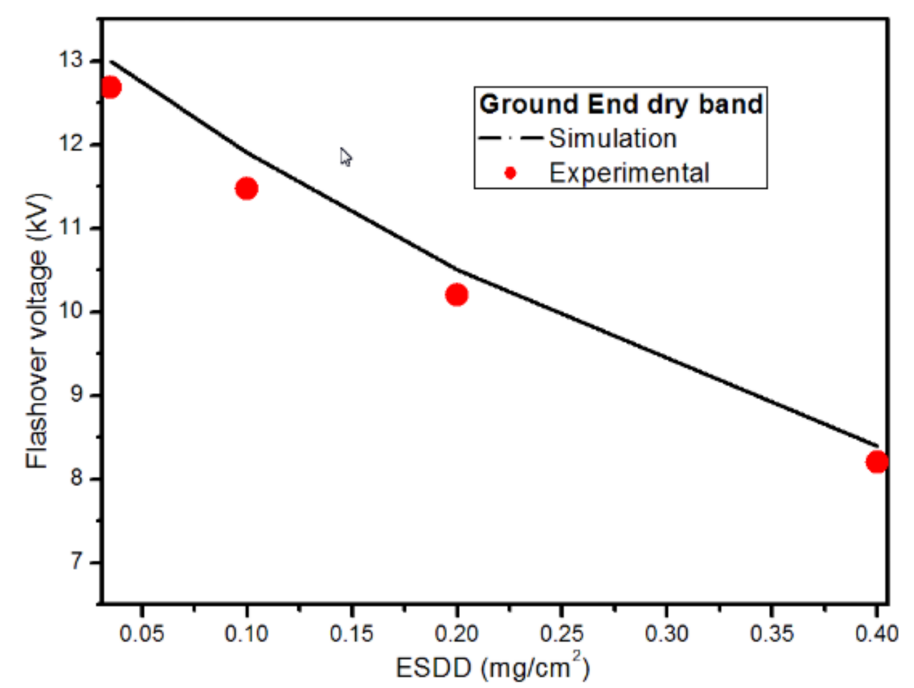

Figure 19. Flashover voltage for different values of ESDD for a dry band located near the ground electrode.

Figure 20 shows simulation and experimental results for a sample having $1 \mathrm{~cm}$ dry band located in the middle of the sample. It was noticed from experimental results that the flashover voltage is higher for middle region dry band than the other two cases (ground and energized end). This might be due to the arc propagation in both directions after originating from the middle region. The difference between simulation and experimental results were found to be higher in this case as compared to uniform pollution layer and high voltage end dry band. This difference in flashover voltage may be due to the uncertainty of arc propagation in either direction in the case of middle dry band. 


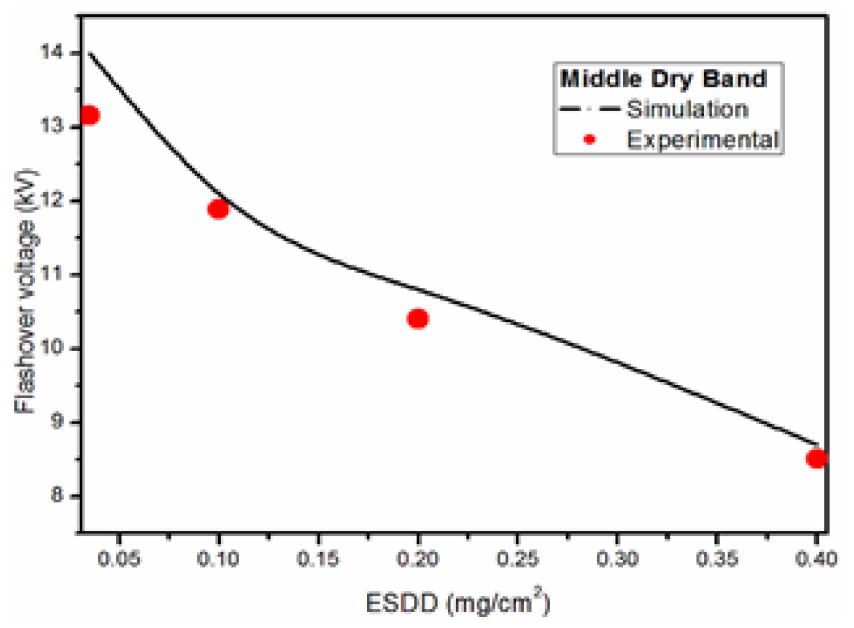

Figure 20. Flashover voltage for a middle dry band configuration at different values of ESDD.

Figure 21 shows the flashover voltage for a two dry band model. Dry bands of $1 \mathrm{~cm}$ width were created near the energized and ground electrode. As expected, a decrease in flashover voltage occurs with increase in ESDD. The experimental and simulation results were found to be in good agreement at higher values of ESDD. At lower values of ESDD, the experimental values of flashover were found to be lower than simulation results. There can be various reasons for the difference between experimental and simulation results such as manual application of pollution, change in hydrophobicity due to room temperature and other tests conditions.

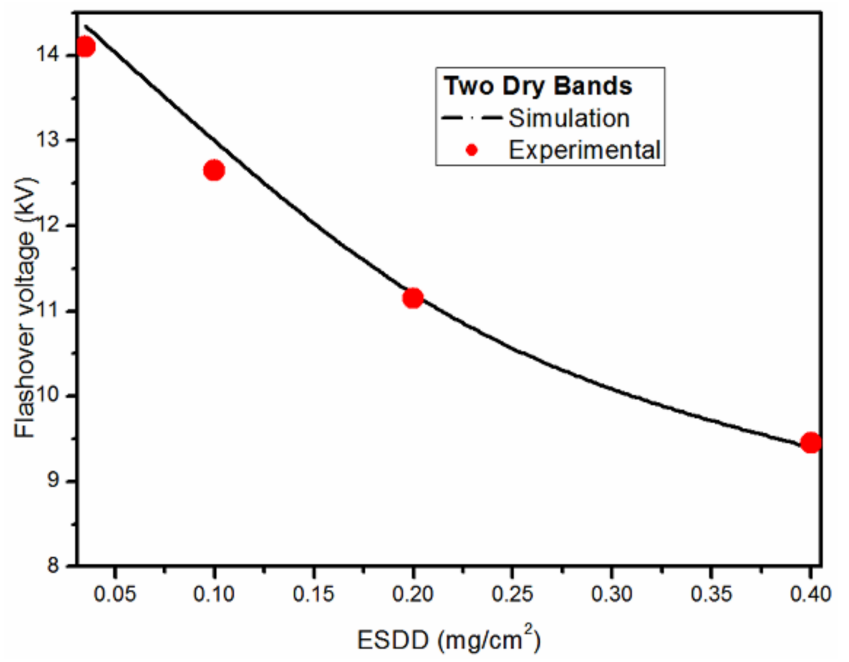

Figure 21. Flashover voltage for two dry bands configuration at different ESDD values.

Figure 22 shows experimental and simulation results of a three dry band model. Flashover voltage decreased with increase in ESDD values. The flashover voltage of a three dry band configuration was found to be higher as compared to single and two dry band configurations. The experimental and simulation results were in good agreement, which validates the accuracy of our proposed mathematical model. 


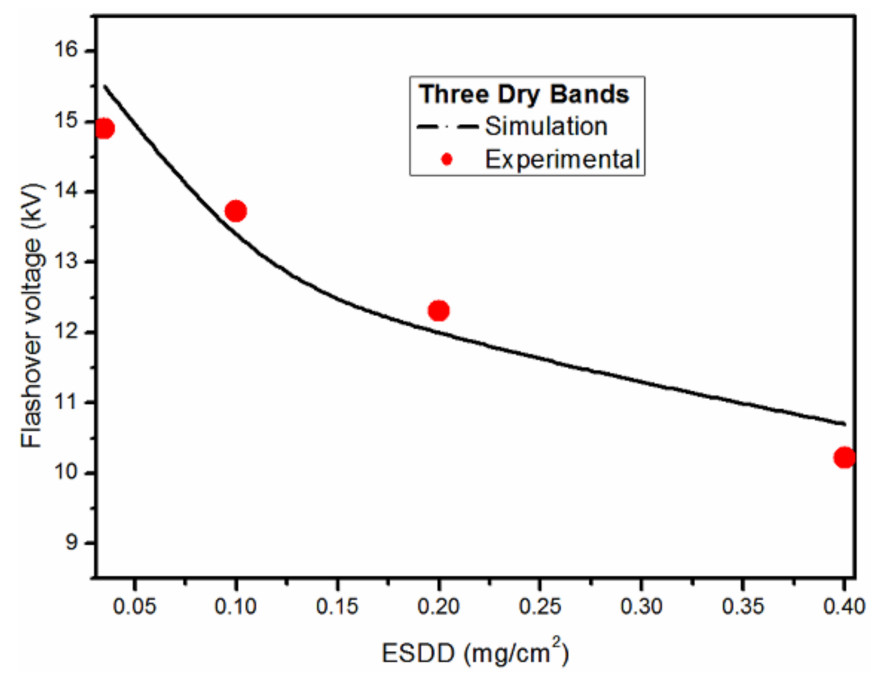

Figure 22. Flashover voltage for three dry bands model at different values of ESDD.

\section{Conclusions}

A dynamic arc model was developed and validated in this paper for single and multiple dry bands. The model was tested for different polluted conditions and dry band configurations. The obtained simulation results were in good agreement with experimental results. The mathematical model presented here has the ability of predicting the flashover voltage of polluted insulators by considering the dynamic nature of flashover arc. The influence of dry band location on critical flashover voltage was also studied using the proposed model. For a single dry band configuration, the maximum discrepancy was found to be between $1.8 \%$ and $5 \%$. In the case of multiple dry bands, the discrepancy was found to be between $1.7 \%$ and $4.6 \%$. The proposed dynamic arc model offers the advantage of predicting critical flashover voltage for different dry band location and considering the inductive effect of flashover arc which was not considered in the existing dynamic arc models. This work can be extended to real insulators under operation conditions by considering insulator form factor in the mathematical model. This will help scientists and engineers in the design and selection of high voltage outdoor insulators for polluted conditions. Furthermore, this model can be used to predict the critical flashover voltage of station post insulators installed in polluted environments where the possibility of multiple dry band formation is very high.

Author Contributions: Conceptualization, A. and M.A.M.; Methodology, A.; Software, M.K.; Validation, M.K., F.U.; Formal Analysis, M.A.M.; Investigation, M.K.; Resources, A.N.; Data Curation, M.K.; Writing-Original Draft Preparation, A.; Writing-Review \& Editing, A.N. and M.A.M.; Visualization, M.A.M.; Supervision, A.N.; Project Administration, A.

Conflicts of Interest: The authors declare no conflict of interest.

\section{References}

1. Ho, K.F.; Lee, S.C.; Chan, C.K.; Jimmy, C.Y.; Chow, J.C.; Yao, X.H. Characterization of chemical species in PM 2.5 and PM 10 aerosols in Hong Kong. Atmos. Environ. 2003, 37, 31-39. [CrossRef]

2. Swift, D.A.; Reynders, J.P.; Engelbrecht, C.S.; Seko-Telento, A.; Fierro-Chavez, J.L. Polluted Insulators: A Review of Current Knowledge; Cigré: Paris, France, 2000.

3. Chrzan, K.; Pohl, Z.; Kowalak, T. Hygroscopic properties of pollutants on HV insulators. IEEE Trans. Electr. Insul. 1989, 24, 107-112. [CrossRef]

4. Jolly, D.C. Contamination flashover theory and insulator design. J. Frankl. Inst. 1972, 294, 483-500. [CrossRef]

5. Rahal, A.M.; Huraux, C. Flashover mechanism of high voltage insulators. IEEE Trans. Power Appar. Syst. 1979, PAS-98, 2223-2231. [CrossRef] 
6. Dhahbi-Megriche, N.; Beroual, A. Predictive dynamic model of the leakage current and flashover voltage of discontinuously polluted insulators under ac voltage: Experimental validation. J. Phys. Appl. Phys. 2007, 40, 7782. [CrossRef]

7. Ghosh, P.S.; Chatterjee, N. Polluted insulator flashover model for ac voltage. IEEE Trans. Dielectr. Electr. Insul. 1995, 2, 128-136. [CrossRef]

8. Prakash, N.B.; Parvathavarthini, M.; Madavan, R. Mathematical Modeling on AC Pollution Flashover Performance of Glass and Composite Insulator. J. Electr. Eng. Technol. 2015, 10, 1796-1803. [CrossRef]

9. El-Zohri, E.H.; Ziedan, H.; Procházka, R. A new proposed dynamic arc model for flashover performance of a non-uniform polluted insulator string under HVAC stress. Electr. Power Syst. Res. 2015, 119, 278-286. [CrossRef]

10. Karady, G.G. Flashover mechanism of non-ceramic insulators. IEEE Trans. Dielectr. Electr. Insul. 1999, 6, 718-723. [CrossRef]

11. Karady, G.G.; Shah, M.; Brown, R.L. Flashover mechanism of silicone rubber insulators used for outdoor insulation-I. IEEE Trans. Power Deliv. 1995, 10, 1965-1971. [CrossRef]

12. Shah, M.; Karady, G.G.; Brown, R.L. Flashover mechanism of silicone rubber insulators used for outdoor insulation-II. IEEE Trans. Power Deliv. 1995, 10, 1972-1978. [CrossRef]

13. Gubanski, S.M. Modern outdoor insulation-concerns and challenges. IEEE Electr. Insul. Mag. 2005, 21, 5-11. [CrossRef]

14. Haddad, A.; Warne, D.F. Advances in High Voltage Engineering; IET: London, UK, 2004; Volume 40.

15. Que, W.; Sebo, S.A. Electric field and potential distributions along non-ceramic insulators with water droplets. In Proceedings of the Electrical Insulation Conference and Electrical Manufacturing \& Coil Winding Conference, Cincinnati, OH, USA, 8 October 2001; pp. 441-444.

16. Guan, Z.; Wang, L.; Yang, B.; Liang, X.; Li, Z. Electric field analysis of water drop corona. IEEE Trans. Power Deliv. 2005, 20, 964-969. [CrossRef]

17. Hampton, B.F. Flashover mechanism of polluted insulation. Proc. Inst. Electr. Eng. 1964, 111, 985-990. [CrossRef]

18. Salthouse, E.C. Initiation of dry bands on polluted insulation. Proc. Inst. Electr. Eng. 1968, 115, $1707-1712$. [CrossRef]

19. Loberg, J.O.; Salthouse, E.C. Dry-band growth on polluted insulation. IEEE Trans. Electr. Insul. 1971, EI-6, 136-141. [CrossRef]

20. Waters, R.T.; Haddad, A.; Griffiths, H.; Harid, N.; Sarkar, P. Partial-arc and spark models of the flashover of lightly polluted insulators. IEEE Trans. Dielectr. Electr. Insul. 2010, 17, 417-424. [CrossRef]

21. Arshad; Nekahi, A.; McMeekin, S.G.; Farzaneh, M. Influence of dry band width and location on flashover characteristics of silicone rubber insulators. In Proceedings of the IEEE Electrical Insulation Conference (EIC), Montreal, QC, Canada, 19-22 June 2016; pp. 73-76.

22. Arshad; Nekahi, A.; McMeekin, S.G.; Farzaneh, M. Flashover Characteristics of Silicone Rubber Sheets under Various Environmental Conditions. Energies 2016, 9, 683. [CrossRef]

23. Arshad; Nekahi, A.; McMeekin, S.G.; Farzaneh, M. Effect of dry band location on electric field distribution along a polymeric insulator under contaminated conditions. In Proceedings of the 2015 50th International Universities Power Engineering Conference (UPEC), Stoke on Trent, UK, 1-4 September 2015; pp. 1-4.

24. Farzaneh, M.; Volat, C.; Zhang, J. Role of air gaps on AC withstand voltage of an ice-covered insulator string. IEEE Trans. Dielectr. Electr. Insul. 2006, 13, 1350-1357. [CrossRef]

25. Taheri, S.; Farzaneh, M.; Fofana, I. Electrical performance evaluation of EHV post insulators covered with ice under different air gap configurations. IEEE Trans. Dielectr. Electr. Insul. 2014, 21, 2619-2627. [CrossRef]

26. Zhang, J.; Farzaneh, M. Modeling of flashover on ice-covered insulators with multi air gaps. In Proceedings of the 2005/2006 IEEE/PES Transmission and Distribution Conference and Exhibition, Dallas, TX, USA, 21-24 May 2006; pp. 109-114.

27. Rizk, F.A.; Parvathavarthini, M.; Madavan, R. Mathematical models for pollution flashover. Electra 1981, 78, 71-103.

28. Jolly, D.C. Contamination flashover, part I: Theoretical aspects. IEEE Trans. Power Appar. Syst. 1972, PAS-91, 2437-2442. [CrossRef]

29. Dhahbi-Megriche, N.; Beroual, A.; Krähenbühl, L. A new proposal model for flashover of polluted insulators. J. Phys. Appl. Phys. 1997, 30, 889. [CrossRef] 
30. Dhahbi-Megriche, N.; Beroual, A. Dynamic model of discharge propagation on polluted surfaces under impulse voltages. IEE Proc.-Gener. Transm. Distrib. 2000, 147, 279-284. [CrossRef]

31. Beroual, A.; Dhahbi-Megriche, N. Dynamic model of discharge propagation on discontinuous pollution layers under AC voltages and experimental validation. In Proceedings of the 2002 Annual Report Conference on Electrical Insulation and Dielectric Phenomena, Cancun, Quintana Roo, Mexico, 20-24 October 2002; pp. 331-334.

32. Slama, M.E.-A.; Hadi, H.; Flazi, S. Investigation on influence of salts mixture on the determination of flashover discharge constant Part I: A preliminary study. In Proceedings of the 2008 Annual Report Conference on Electrical Insulation and Dielectric Phenomena, Quebec, QC, Canada, 26-29 October 2008; pp. 674-677.

33. Slama, M.E.-A.; Beroual, A.; Hadi, H. Analytical computation of discharge characteristic constants and critical parameters of flashover of polluted insulators. IEEE Trans. Dielectr. Electr. Insul. 2010, 17, 1764-1771. [CrossRef]

34. Sundararajan, R.; Gorur, R.S. Dynamic arc modeling of pollution flashover of insulators under dc voltage. IEEE Trans. Electr. Insul. 1993, 28, 209-218. [CrossRef]

35. Farzaneh, M.; Zhang, J. A multi-arc model for predicting ac critical flashover voltage of ice-covered insulators. IEEE Trans. Dielectr. Electr. Insul. 2007, 14, 1401-1409. [CrossRef]

36. Taheri, S.; Farzaneh, M.; Fofana, I. Dynamic modeling of AC multiple arcs of EHV post station insulators covered with ice. IEEE Trans. Dielectr. Electr. Insul. 2015, 22, 2214-2223. [CrossRef]

37. Volat, C.; Farzaneh, M.; Mhaguen, N. Improved FEM models of one-and two-arcs to predict AC critical flashover voltage of ice-covered insulators. IEEE Trans. Dielectr. Electr. Insul. 2011, 18, 393-400. [CrossRef]

38. Dhahbi-Megriche, N.; Beroual, A. Self-consistent multi-arcs dynamic model for high voltage polluted insulators. IEEE Trans. Dielectr. Electr. Insul. 2016, 23, 2899-2907. [CrossRef]

39. Mayer, O. Beitrag zur Theorie der Statischen und der Dynamishchen Litchbogens. Arch. Elektrotechnik 1943, 37, 588-608. [CrossRef]

40. He, L.; Gorur, R.S. Source strength impact analysis on polymer insulator flashover under contaminated conditions and a comparison with porcelain. IEEE Trans. Dielectr. Electr. Insul. 2016, 23, 2189-2195. [CrossRef]

41. Fofana, I.; Beroual, A. A predictive model of the positive discharge in long air gaps under pure and oscillating impulse shapes. J. Phys. Appl. Phys. 1997, 30, 1653. [CrossRef]

42. Fofana, I.; Beroual, A. A model for long air gap discharge using an equivalent electrical network. IEEE Trans. Dielectr. Electr. Insul. 1996, 3, 273-282. [CrossRef]

43. Wilkins, R. Flashover voltage of high-voltage insulators with uniform surface-pollution films. Proc. Inst. Electr. Eng. 1969, 116, 457-465. [CrossRef]

44. Fofana, I.; Beroual, A. Predischarge models in dielectric liquids. Jpn. J. Appl. Phys. 1998, 37, 2540. [CrossRef]

45. Hesketh, S. General criterion for the prediction of pollution flashover. Proc. Inst. Electr. Eng. 1967, 114, 531-532. [CrossRef]

(C) 2018 by the authors. Licensee MDPI, Basel, Switzerland. This article is an open access article distributed under the terms and conditions of the Creative Commons Attribution (CC BY) license (http://creativecommons.org/licenses/by/4.0/). 